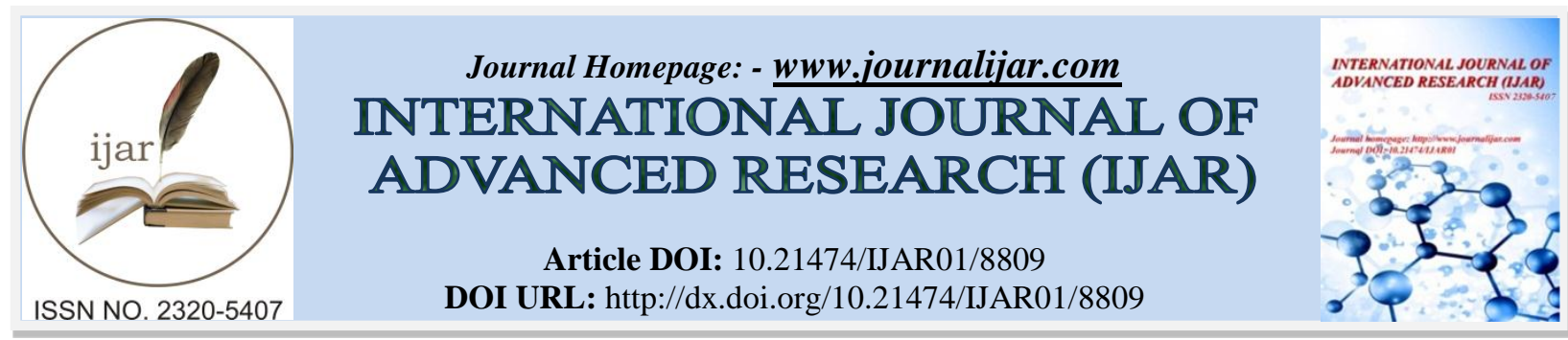

RESEARCH ARTICLE

\title{
INCIDENTAL FINDING OF T1 SPINA BIFIDA IN YOUNG FEMALE WITH CERVICAL SPONDYLOSIS.
}

Dr. Mazharuddin Ali Khan ${ }^{1}$, Dr. Syed Yaser Quadri ${ }^{2}$ and Dr. Wasif Ishaqui ${ }^{3}$.

1. Department of Orthopedics, Professor and Head of Department, Owaisi Hospital and Research Centre, Deccan college of medical sciences.

2. Department of Orthopedics, Assistant Professor, Owaisi Hospital and Research Centre, Deccan college of medical sciences.

3. Department of Orthopedics, Post-Graduate, MS Orthopedics, Owaisi Hospital and Research Centre, Deccan college of medical sciences.

\section{Manuscript Info}

Manuscript History

Received: 04 February 2019

Final Accepted: 06 March 2019

Published: April 2019

\section{Key words:-}

T1 spina bifida, cervical spine $\mathrm{x}$-ray, cervical spondylosis.

\section{Abstract}

We report a 35-year-old female patient who was admitted to our orthopedic department with neck pain for 2 months, radiating to right shoulder and arm region associated with numbness, tingling and paresthesia, with no recent history of any trauma, injury, fall or accident. We have found accidentally a dorsal spinous process schisis, a very rare vertebral abnormality, that we recognized in the $\mathrm{X}$ ray cervical spine performed in view of neck pain/cervical spondylosis.

Copy Right, IJAR, 2019,. All rights reserved.

\section{Introduction:-}

Human vertebral spine could be affected by a wide range of anatomical variants of the body and/or the neural arch as well as accessory bones. These anatomical variants include hemivertebra, block vertebrae fused vertebra, unfused vertebra, butterfly vertebra, hyperplasia or hypoplasia of laminae and spinous process They usually affect the cervical and lumbar spine as reported in literature, and frequently they are correlated with neural elements abnormalities. The pathophysiology describes a migration failure of sclerotome cells during embryogenesis because of several chromosomal alterations or specific microenvironmental influences (as radiations, teratogenic substance, drugs).

\section{Case presentation}

A 35-year-old female was admitted in our orthopedic department with neck pain for 2 months, originating at lower aspect of neck, radiating to right shoulder and arm associated with numbness, tingling sensation and paresthesia's, increased with moderate exertion and bending down. There is difficulty in carrying out activities of daily life like combing hair, wearing clothes, cleaning utensils and cooking and other ADL. Examination of cervical spine done, there was mild restriction of range of movements at cervical region, with positive Spurling's sign and Lhermitte sign. There was no sensory or motor impairment, Upper limb power [shoulder, arm, forearm] (R/L) 5/5, Upper Limb reflexes biceps(R/L) 2/4, triceps(R/L) 2/4, supinator (R/L) 2/4. Range of moments at shoulder(R/L), Elbow(R/L) and Wrist $(\mathrm{R} / \mathrm{L})$ were normal. There is no recent history of any blunt trauma, fall and injury to spine region, no history to fever, weight loss, anorexia, or weakness in one or both upper/lower limbs noted. Vitals at time of admission were stable.

Corresponding Author:- Mazharuddin Ali Khan. 
The neck pain was investigated through x-ray examination of the cervical spine in anteroposterior and lateral projections. On the anteroposterior projection, we noticed an oblique radiotransparent line in correspondence of the spinous process of the first thoracic vertebrae and also early changes of degeneration and straightening of spine as result of spasm of neck muscles.

CT scan of cervical spine done which revealed T1 spina bifida

\section{Discussion:-}

Congenital anomalies of spine are quite common and most of these anomalies are localized at cervical and lumbar spine but anomalies at thoracic spine is rare. Spinal Deformities can be divided into congenital and acquired forms. Congenital forms are mainly divided into 2 types: segmentation and development defects. Unilateral unsegmented bars and bilateral segmentation defects belong to the first group. On the other side, developmental defects include hemivertebrae and failure of fusion of neural tube which includes, in turn, the simple cleft of the posterior arch of the vertebrae (spina bifida occulta) and spina bifida[1]The most frequent spinal anomalies are represented by synostosis, vertebral schisis or spina bifida, hemivertebrae, spondylitis, spondylolisthesis, sacralization of L5, cervical rib, congenital absence or hypoplasia of a cervical pedicle, vertebral hypoplasia, dysplasia of the vertebral arch, doubled spinous process, and unilateral hyperplasia of a spinous process.[2],[3],[4],[5].

Failure to close the neural tube, or a reopening after a physiological closure, can lead to various defects, which may involve, individually or in toto, the neural tissue, the meninges, bones, and the overlying soft tissues. The overall incidence of the closing neural tube defects, during pregnancy, has been estimated to be between $4 \%$ and 5\% [6]. Several factors may contribute to determine these anomalies: environmental factors, hereditary, toxic substances, food, and metabolic disorders (e.g., folate deficiency seems to play a key role in the development of spina bifida).

During the end of the third week of pregnancy, the somitomere, begin to develop and from these ones, the somites followed by sclerotome, myotome and dermatome take shape. The vertebrae are derived by the evolution of sclerotome, which is the closest portion of the somites to embryonic axis. The further differentiation of the sclerotome cells depends on their position because of further migration in relation to the action induced by surrounding tissues. In fact, notochord cells induce the development of the vertebral bodies from sclerotome whereas the neural tube induces differentiation of sclerotome in vertebral arches components. The first ossification centers appear from the second month of gestation. The spinous process has not an own ossification nucleus, with the exception of the tip, and appears during the first year of life for the fusion of the endochondral growth from both vertebral arches. The lack of fusion or defective closure of the neural tube on the median line, due to a defective growth of the blades of one or more vertebral arches, determines spinal dysraphism or spina bifida.

These anomalies can occur at any level of the spine, although it is more frequently found at the lumbosacral level and more rarely in the cervical area.

In this report, we describe a case of asymptomatic simple $\mathrm{T} 1$ spina bifida, most frequent type and the simplest neural tube defect, due to the lack of fusion, on the middle line of the two side laminae of the fetus spine during the first month of pregnancy; the space between the laminae is usually filled by fibrotic tissue with a partial outline of the spinous process. The most affected vertebrae are mainly L5 and S1. This anatomic variant seems not to cause symptoms and it is often reported incidentally in patients who perform diagnostic examinations (x-ray, CT scan) for other reasons. CT scan allows the identification of this anomaly and, thus the best therapeutic decision, which may also include surgery. An important role is played by the evaluation of the interlaminar distance. If the interlaminar distance is small, the interlaminar gap is usually filled by fibrous tissue, and it rarely causes symptoms. If the gap is larger, due to a reduced growth of the vertebral laminae or by greater distance between them, it can develop a meningocele or myelomeningocele which may give rise to symptoms and requires surgical repair. Sometimes this kind of anatomic variants could be associated with spinal cord anomalies and it might be helpful to perform an MRI study to recognize them.

\section{Conclusion:-}

We have described a rare case of thoracic vertebral failure of fusion at T1 level in a young female, to describe the main radiological features pointed out by the CT scan study associated with volume rendering reconstructions and $\mathrm{x}-$ 
ray examination. We think that this case report may be helpful to radiologists, orthopedists, neurologists, and neurosurgeons to consider this singular finding.

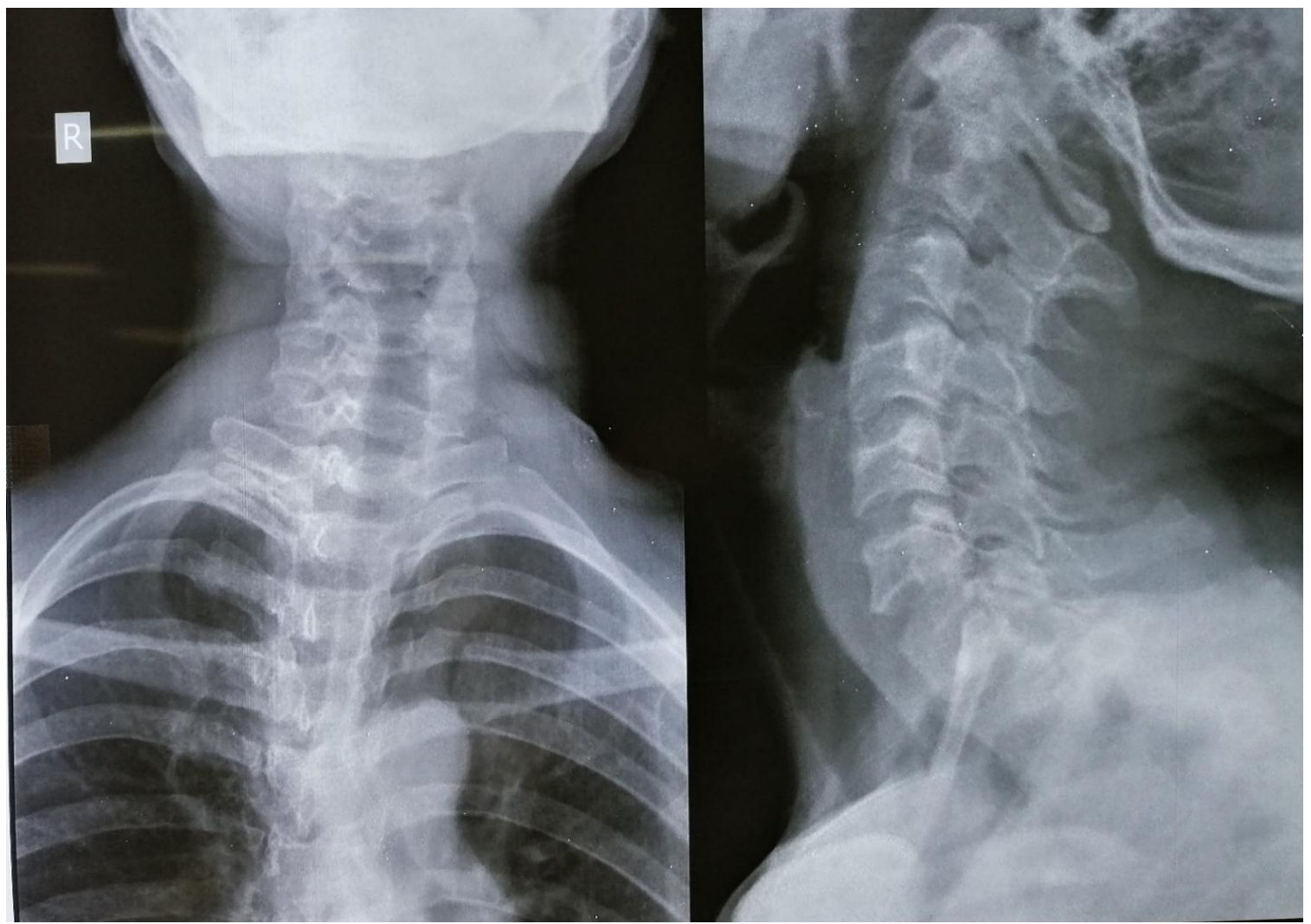

Fig. 1. Cervical spine $x$-ray anteroposterior (AP) projection showing an oblique radiotransparent line in correspondence of the spinous process of the first thoracic (T1) vertebrae.

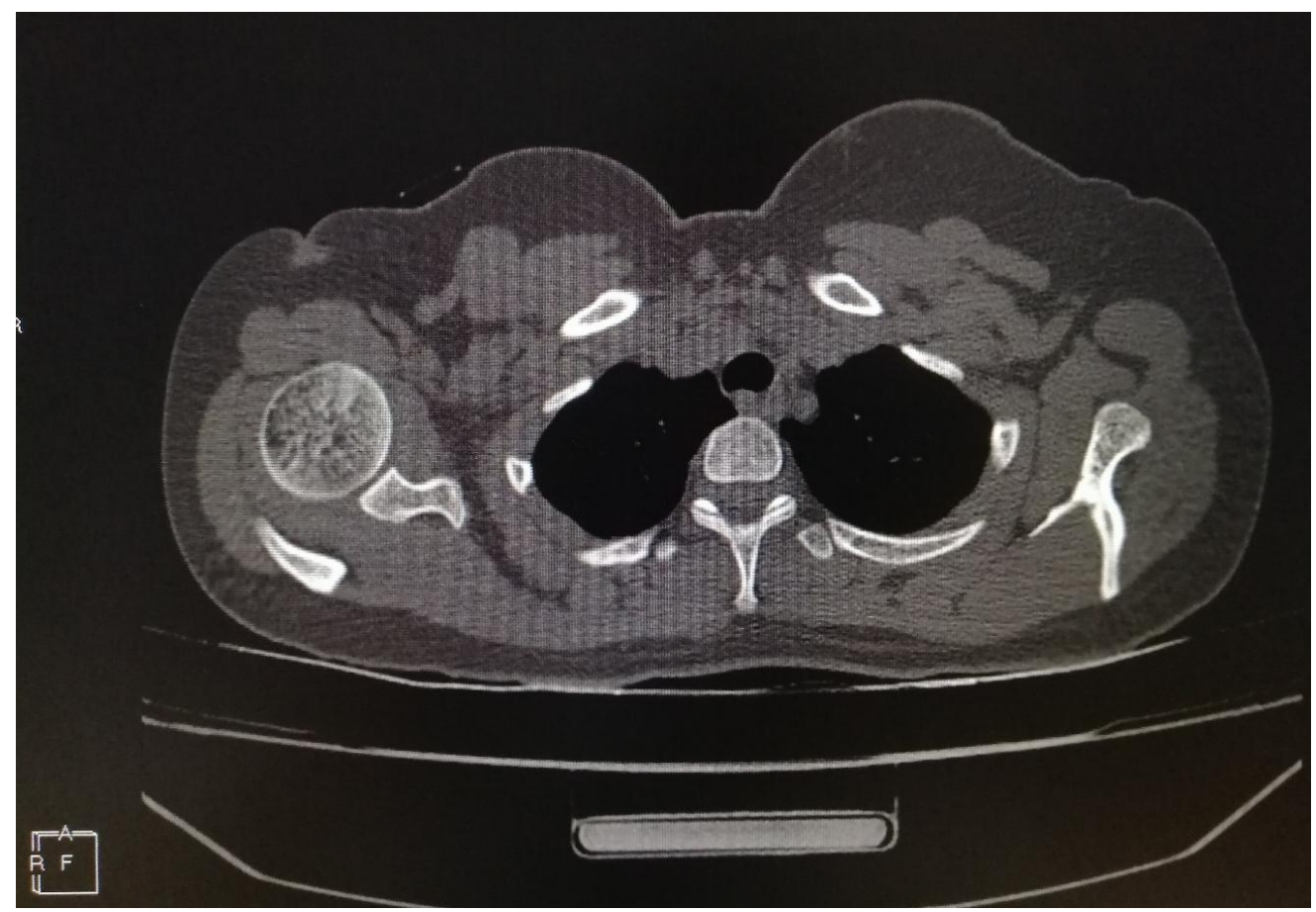

Figure 2 showing CT scan axial view at T1 level showing T1 spina bifida 


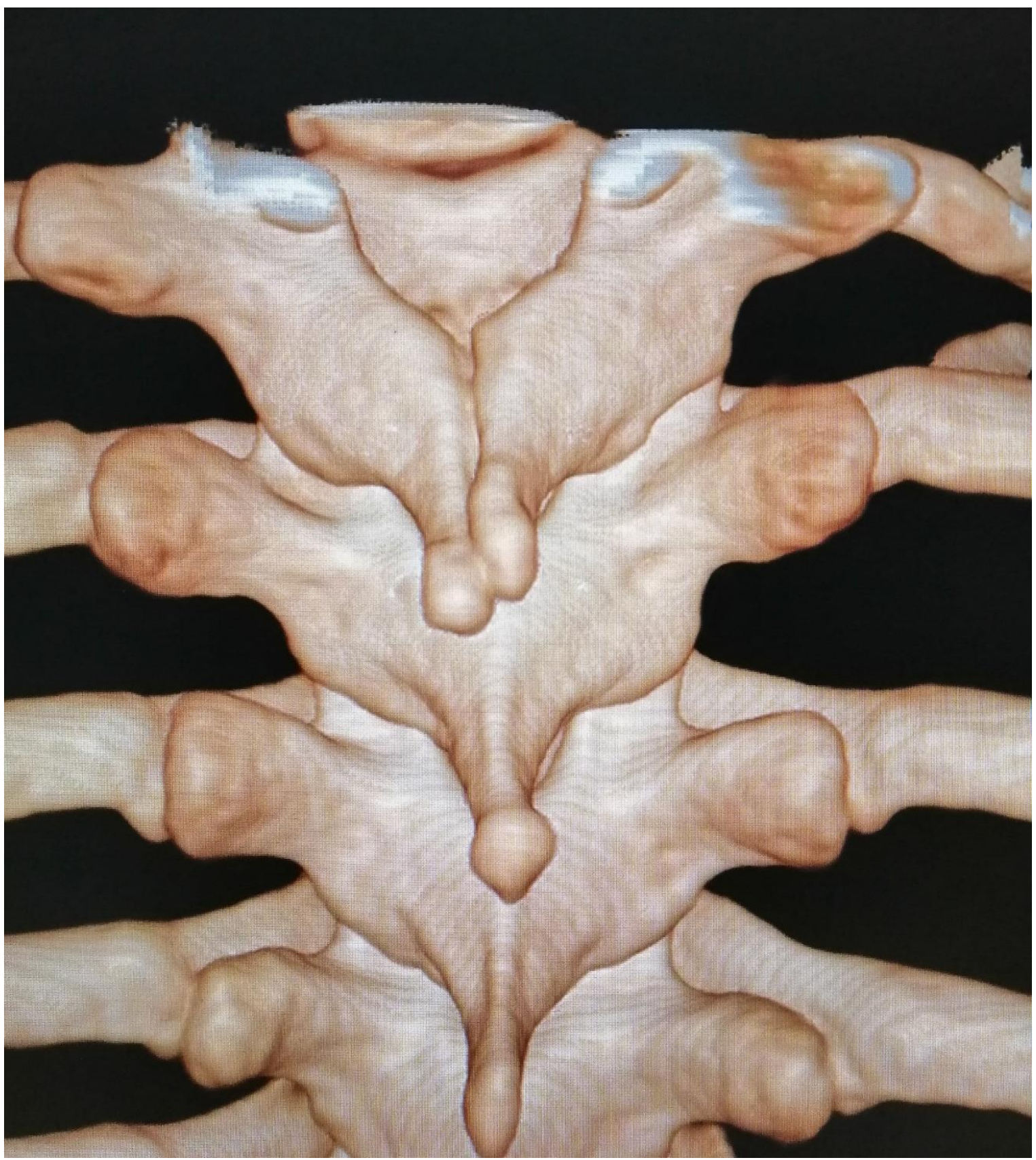

Figure 3: 3D CT of cervical spine showing T 1 spina bifida 


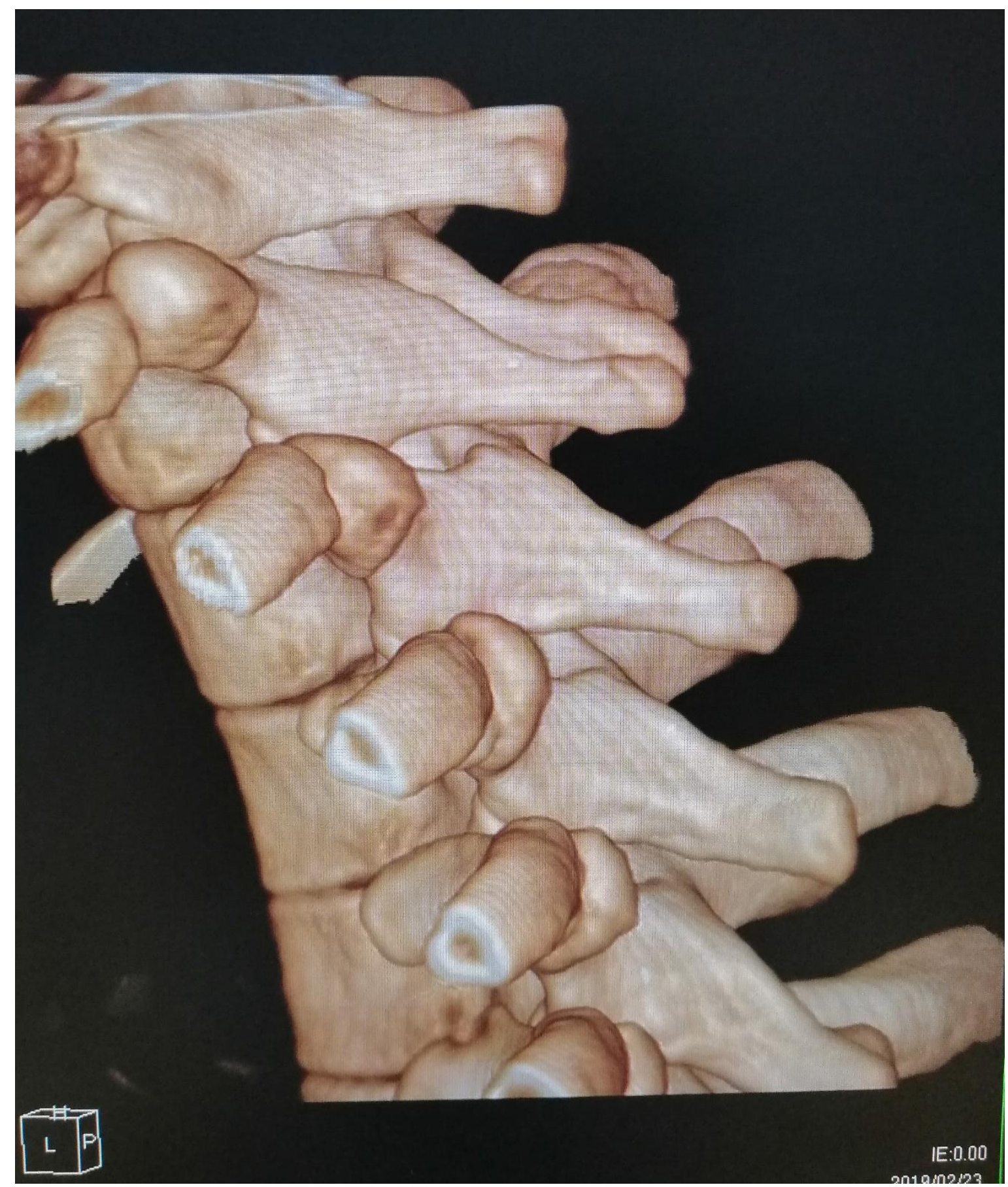

Fig. 4. 3D CT scan in the axial plane of the cervical spine showing the defect of fusion of T1 spinous process. 


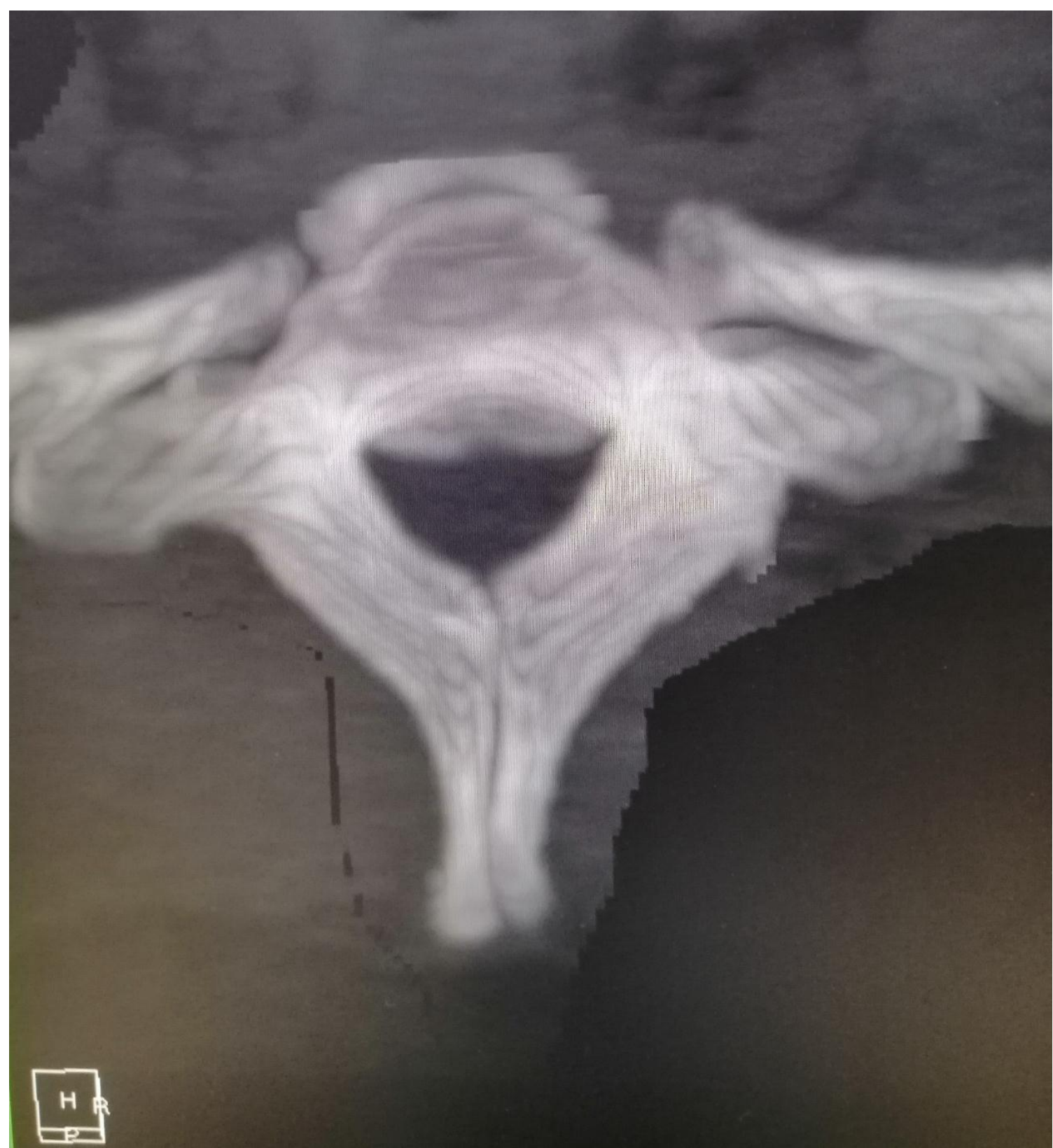

Figure 5 showing Maximum intensity projection(MIP) image at T1 spinal vertebrae level showing T1 spina bifida.

\section{Competing Interests:}

The authors declare that they have no competing interests.

\section{Acknowledgements and Funding:}

Nil

\section{Clinical Message:-}

$\mathrm{T} 1$ spina bifida is a rare spinal deformity which usually gets detected in asymptomatic patients coming with some other neck and chest pathology, Symptomatic individuals usually presents with upper limb weakness, hand grip weakness, and sensory disturbances. Surgery is the treatment of choice in symptomatic individuals, and in asymptomatic individuals, no specific treatment is required. 


\section{References:-}

1. F. Postacchini, A. Ferretti, E. IppolitoCollo e tronco

2. Antonio Delfino (Ed.), Ortopedia e Traumatologia \& Medicina Fisica e Riabilitativa (2nd edn), Antonio Delfino Editore medicina-scienze, Rome (2009), pp. 239-240

3. S. Das, V. Kapur, R. SuriA duplicated spinous process of the $\mathbf{C 7}$ vertebra

4. Folia Morphol (Warsz), 64 (2) (2005), pp. 115-117

5. C.M. Heyer, V. Nicolas, S.A. PetersUnilateral hyperplasia of a cervical spinous process as a rare congenital variant of the spine

6. Clin Imaging, 31 (6) (2007), pp. 434-436

7. K. ReinhardtAn unusual abnormality of the spinal process of the 5th, 6 th and 7 th cervical vertebrae

8. Fortschr Geb Rontgenstr Nuklearmed (German), 85 (2) (1956), pp. 253-255

9. M.D. Wiener, D.A. Forsberg, S. MartinezCongenital absence of a cervical spine pedicle: clinical and radiologic findings

10. Am J Roentgenol, 155 (5) (1990), pp. 1037-1041

11. V. Kumar, A.K. Abbas, N. FaustoRobbins and Cotran pathologic basis of disease

12. (7th edition), Elsevier Inc, Milano (2006) 